\title{
Fit to be interviewed by the police?
}

\author{
Keith J. B. Rix
}

Although police surgeons (or forensic medical examiners; FMEs) usually assess fitness to be interviewed by the police (Norfolk, 1996), psychiatrists may also be asked for an opinion (Protheroe \& Roney, 1996).

\section{The importance of fitness to be interviewed}

Recent miscarriages of justice have occurred as a consequence of unreliable confessions to the police. A well-known illustration is the case of Engin Raghip, who was convicted of the murder in the Broadwater Farm riots of PC Blakelock. Prior to his trial it was known that he had a history of what were described as "serious learning difficulties" and had been recommended to attend a special school (Gudjonsson, 1992). His successful appeal (R. $v$. Raghip, 1991) turned on the evidence of Gudjonsson, a forensic psychologist responsible for research relating to factors such as suggestibility and compliance as they affect the reliability of confessions (Gudjonsson \& MacKeith, 1988; Gudjonssonet al, 1993). His evidence included reference to Raghip having a verbal IQ of 73 and a performance IQ of 77.

\section{The law relating to fitness to be interviewed}

Although 'fitness to be interviewed' is not in the Police and Criminal Evidence Act 1984 (PACE) or its Codes of Practice (Home Office, 1995; hereafter, the Codes), except in relation to intoxication, it may arise as an issue in relation to PACE.
Section 76(2) allows the judge to exclude confession evidence if the prosecution cannot prove beyond reasonable doubt that it was not obtained by oppression or in consequence of anything said or done which was likely to have made it unreliable. Section 78(1) gives the judge discretion to exclude a confession when the defence can prove, on a balance of probabilities, that its admission would adversely affect the fairness of the proceedings. Relevant circumstances include psychiatric aspects of the accused. If attempts to have confession evidence excluded fail under sections 76 and 78 , section 82(3) gives the judge further discretionary power to exclude evidence. There is also similar power under common law.

PACE also includes specific provision for the mentally handicapped. The judge must warn the jury that there is special need for caution before convicting a mentally handicapped person, if the confession was not made in the presence of an independent person and the case depends wholly or substantially on it. R. $v$. McKenzie (1992) established that when the prosecution's case depends wholly on a confession and the defendant suffers from "a degree of mental handicap" and the confession is "unconvincing to a point where a jury properly directed could not properly convict", the judge should withdraw the case from the jury. The law does not define "a degree of mental handicap".

Against this background, the police may seek an opinion on 'fitness to be interviewed'. This should be distinguished from the broader notion of the 'reliability' of interview material. Someone may be 'fit to be interviewed' but there might still be a question as to the degree of reliability that should be attributed to the interviews. The interviews might be removed from the trial entirely following a voire dire (see below), or there might be expert evidence that downgrades the evidential weight given to the interview within the trial and before the jury.

Dr Keith Rix, FRCPsych, is a Consultant Psychiatrist in the Leeds Community and Mental Health Services Teaching NHS Trust and a Visiting Consultant Psychiatrist at HM Prison, Leeds. He is a Member of the Association of Police Surgeons. This paper arises out of his experience in working with the police in West Yorkshire over the past 13 years. He has given evidence in a number of cases in which fitness to be interviewed has been an issue, and he is a Member of the Academy of Experts. His address is High Royds Hospital, Menston, Ilkley, West Yorkshire LS29 6AQ. 


\section{The police interview}

When a possible crime has been committed the police gather evidence. They interview witnesses and suspects. If the suspect is charged, the interview is likely to become evidence. The prosecution may use it to try to prove guilt. The defence may either rebut it or attempt to use it to infer not the defendant's guilt but his or her innocence. Or they may use it to attempt to infer the defendant's guilt of a lesser offence, or that she or he has a psychiatric defence such as insanity or diminished responsibility.

Conduct of interviews is a subject of the Codes. Compliance should ensure that the courts have reliable, accurate and complete evidence. This reduces the likelihood of a miscarriage of justice. Interviews usually take place in designated rooms in police stations. Two police officers are present and both may ask questions. The suspect's legal representative may be present and, in some cases, an 'appropriate adult'. A solicitor may object to inappropriate questions or reference to matters not material to the enquiry. The appropriate adult may intervene if he thinks that a question is misleading or has not been understood. Subsequently, selective, typed transcripts are prepared. If necessary, complete transcripts can be prepared and part or all of the tapes may be played to assist a jury in reaching a verdict.

\section{Special provisions for the mentally disordered}

\section{Code $\mathrm{C}$ states that:}

If an officer has any suspicion, or is told in good faith, that a person of any age may be mentally disordered or mentally handicapped, or mentally incapable of understanding the significance of questions put to him or his replies, then that person shall be treated as a mentally disordered or mentally handicapped person.

\section{Definitions of mental disorder and mental handicap}

'Mental disorder' is as defined in section 1(2) of the Mental Health Act 1983:

mental illness, arrested or incomplete development of mind, psychopathic disorder and any other disorder or disability of mind.

The Code does not exclude substance-related disorders. 'Mental handicap' is different but calls for the same provision. Even if IQ test results are known before the interview, the courts do not adhere to IQ 69/70 as an absolute dividing line for identifying mental handicap. In R. $v$. Raghip (1991), the Court of Appeal judges stated that they were:

not attracted to the concept that the judicial approach to submissions under section 76(2)(b) should be governed by which side of an arbitrary line, whether at $69 / 70$ or elsewhere, the IQ fell.

\section{The role of the appropriate adult}

The Code acknowledges that although

people who are mentally disordered or mentally handicapped are often capable of providing reliable evidence, they may without knowing or wishing to do so, be particularly prone in certain circumstances to provide information which is unreliable, misleading or self-incriminating.

\section{Therefore:}

special care should ... always be exercised in questioning such a person, and the appropriate adult should be involved, if there is any doubt about a person's ... mental state or capacity.

The Code states who can be an appropriate adult (Box 1) and advises that:

it may ... be more satisfactory ... if [he] is someone who has experience or training in their care rather than a relative.

It cannot be a solicitor or 'lay visitor' who is present at the police station in that capacity.

Box 1. Paragraph 1.7(b) of Code $C$ of the Police and Criminal Evidence Act 1984 states that 'the appropriate adult' means

A relative, guardian or other person responsible for his care or custody;

Someone who has experience of dealing with mentally disordered or mentally handicapped people but is not a police officer or employed by the police (such as an approved social worker as defined by the Mental Health Act 1983 or a specialist social worker); or

Failing either of the above, some other responsible adult aged 18 or over who is not a police officer or employed by the police 
The Code states the role of the appropriate adult:

He is not expected to simply act as an observer ... the purposes ... are, first, to advise the person being questioned and to observe whether or not the interview is being conducted properly and fairly, and secondly, to facilitate communication.

It is therefore necessary to see the suspect beforehand.

In R. $v$. Dutton (unreported case no. 4627.G1/87, details available from author), a 42-year-old man, who was born in a psychiatric ward where his mother was an in-patient, attended a residential school for retarded pupils and was considered mildly mentally handicapped with a mental age of 13 years and an IQ of 60, was convicted of sexual offences. The trial judge acknowledged that the police should have requested an appropriate adult for the interview with a prisoner whom they knew had attended a school for retarded pupils and been subject to a hospital order under the Mental Health Act. However, he allowed the confession evidence to be put to the jury. The appellant successfully appealed against conviction and the Court of Appeal judges explained:

... paragraph $\mathrm{C} 13$ is intended to deal with ... an interview by the police of a person who is mentally handicapped or at least probably so. It is notorious that such people may be prone to fantasize and may on occasions admit to crimes they have not committed ... we believe that ... (a) the appropriate adult would, before the police interview, have ascertained ... quietly and without any pressure, what he wished to say; and/or (b) ... ensured that Mr Dutton had the advice of a solicitor before he was interviewed. It follows that if Mr Dutton had been accorded the assistance of a responsible adult, he might well have made no admission at all. Certainly, we cannot be sure that he would nevertheless have made the admissions he did make.

\section{Assessing fitness}

\section{Preparation}

The psychiatrist should obtain as much information as possible before seeing the suspect (Box 2). If the suspect is in police custody, there may be time constraints imposed by compliance with PACE ('the PACE clock').

The custody record details what happens to the person in custody and is used to prompt and record compliance with PACE. The records of assessments and reviews may give clues concerning the mental state of the suspect. Many decisions about fitness to be interviewed are made by FMEs. Discussion with the FME may not only assist the psychiatrist in addressing the issue but the FME will usually be more familiar with police procedures and PACE. With modern electronic communications it is occasionally possible to have access to a suspect's medical records with his or her consent.

\section{Consent}

The suspect is under no obligation to undergo psychiatric examination, whether at the request of the police or his own solicitors. However, few refuse. As in any medical consultation, consent, which does not need to be written, must be based on a proper understanding of the nature and purpose of the consultation and must be freely given.

The psychiatrist introduces himself and where he works, and explains who has requested that he attend, referring to his provision of a second opinion on the suspect's health so as to advise the police officers who question and look after the suspect. Impartiality and independence are explained, reference is made to the records, their location, their evidential status, their availability to both the prosecution and the defence and how anything said about the alleged offence may be used at trial. The suspect is advised that he does not have to say anything about the alleged offence. Finally, the psychiatrist explains that he will write a brief summary in the custody record where it can be read by the custody and interviewing officers and by the suspect's own solicitor, and later, if requested, prepare a report or statement for the police, the Crown Prosecution Service or the suspect's solicitors.

The suspect is asked whether he understands, questions are answered and with agreement the examination proceeds.

\section{Setting}

The examination will usually be in the FME's room. If not, the psychiatrist should insist on a room with chairs and a desk or table. Exceptionally, a police

Box 2. Preparation for assessment

Speak to arresting police officers

Observations of custody sergeant

Study custody record

Discuss with the FME

Speak to suspect's own psychiatrist and/or a relative

Obtain hospital records 
officer may be present. Solicitors have no right to be present but the doctor has no right to exclude them, particularly if the suspect wants the solicitor to be present. The solicitor can usually accept exclusion if either the psychiatrist indicates that his records will be available or if the psychiatrist agrees not to ask about the alleged offence.

\section{The format of the examination}

Flexibility is important. Slavish adherence to a scheme can be counter-productive. Psychiatrists who are frequently called to police stations develop their own styles. Nevertheless, there is much to be said for history, mental state and physical examination.

In view of the importance of the suspect's ability to understand the police caution in assessing fitness to be interviewed (Gudjonsson, 1995), an important aspect of the psychiatric examination is the suspect's ability to understand the psychiatrist's explanation. In the case of a woman with an IQ of 73 who was aged 19 years and was six months pregnant when charged with murder (R. v. McGovern, 1990), it was part of her successful appeal against conviction for manslaughter that the incriminating confession occurred without a solicitor when she was

physically ill, emotionally distressed and unable to understand the caution until it was explained in simple language.

The first element of the history is the arrest. Sensitive and empathic questioning about this helps establish rapport through focus on the suspect's current distress. Also, there may be clues at this stage concerning disorientation, memory impairment or clouding of consciousness.

An account is taken of the family and personal history, including recent life events and circumstances. Enquiry about special schooling, reading or writing difficulties and extra tuition or special classes may identify the mentally handicapped. Personality is assessed. Submissiveness, compliance with authority figures and dependence on others may point to suggestibility and compliance, which can affect reliability. While taking a history, the psychiatrist notes the intellect of the person and notes how easily he or she understands questions.

An account of the suspect's medical and psychiatric history is obtained with enquiry as to current physical symptoms. Evidence for physical illness in the appeal of McGovern was that she had been vomiting in her cell before the interview.

Mental state examination begins as soon as the suspect enters the room. Relevant observations can be made under the usual headings. Form of thought or speech, mood, abnormal beliefs or perceptions, and cognition are important. A detailed account
Box 3. Norfolk's suggestions for assessing cognition and intellect

Is he aware of why he is at the police station?

Does he understand his rights?

Do you need money in order to have a solicitor help you at the police station? If you don't want a solicitor to help you now, can you change your mind later?

Does he understand the police caution? ('You do not have to say anything. But it may harm your defence if you do not mention when questioned something which you later rely on in court. Anything you do say may be given in evidence.')

should be recorded, including performance on any tests of intelligence or cognition. Standardised tests have the advantage of repeatability and help to compare findings. However, tests of more immediate relevance may assist more (Norfolk, 1997, in press; Box 3).

In some cases reliability may be challenged on the basis of the suspect's suggestibility, compliance or intelligence. Tests are available to measure these. However, psychiatrists would be wise to avoid the use of psychological tests with which they are not familiar. In order to examine the reliability of the interview, further and more expert assessment may be essential. Proper assessment of compliance, suggestibility or acquiescence depends on sophisticated assessment of 'traits' by a psychologist. Part of the assessment of reliability involves relating such traits to the actual interviews in order to show whether or not they are unreliable as a consequence of their influence.

The FME may have conducted a physical examination but the psychiatrist should be equipped to do so. This is particularly important when an organic disorder is suspected, or if the suspect may be under the influence of, or withdrawing from, intoxicants.

\section{Psychiatric disorders affecting fitness to be interviewed}

Only exceptionally may a 'person who is unfit through drink or drugs to the extent that he is 
unable to appreciate the significance of questions put to him and his answers' (Code C, 12.3; Home Office, 1995) be interviewed. In such a circumstance it is likely that an FME will have advised, but occasionally the psychiatrist may suspect intoxication which has been missed.

Box 4 lists psychiatric disorders that, in most cases, will render a suspect unfit to be interviewed because there would be a substantial risk of an unreliable confession. It is not an exhaustive list. The criterion should probably be that the person's mental state is such that there is a substantial risk that reliance on their answers to questions put by the police could result in a miscarriage of justice.

Box 5 lists psychiatric disorders that may make a suspect vulnerable but do not necessarily lead to 'strictly inadmissible' evidence, if an appropriate adult is present. Even in the presence of mental disorder the courts may rely on interviews with mentally disordered persons in the absence of an appropriate adult, if a doctor assessed the suspect first and was satisfied that they were fit to be interviewed, and this opinion can be sustained. In R. v. Crampton (1990), an unsuccessful appeal was made by a drug addict whose incriminating admission had been made when he was withdrawing from opioid drugs. It was ruled:

Whether or not someone who is a drug addict is fit to be interviewed, in the sense that his answers can be relied upon as being truthful, is a matter for judgment of those present at the time.

\section{Other relevant factors affecting fitness to be interviewed}

Gudjonsson (1992) has identified three types of false confession: voluntary, coerced-compliant and coerced-internalised. His voluntary type is illustrated by the schizophrenic who is deluded concerning his involvement in a crime, or the person with a depressive illness who makes a false confession as a means of expiating guilt. Routine psychiatric assessment ought to identify these. The

Box 4. Psychiatric disorders that will usually lead to unfitness to be interviewed

Acute organic reactions (including severe alcohol or drug withdrawal states)

Mania

Severe dementia

Severe mental handicap
Box 5. Psychiatric disorders that may indicate a significant risk of unreliability

Milder forms of dementia

Hypomania

Schizophrenia and related disorders

Depressive disorders

Mild or moderate mental handicap

Mild substance withdrawal states

other types may not be so readily recognisable and considerations concerning their reliability may require psychological assessment.

Although a psychiatrist may be able to make a preliminary assessment of IQ or personality characteristics such as compliance and suggestibility, these areas should be explored by a psychologist who can also administer the Gudjonsson Suggestibility Scales (Gudjonsson, 1984; 1987) and Compliance Questionnaire (Gudjonsson, 1989). These instruments are useful in assessing those who make a coerced-compliant false confession, where the main feature is the need to escape from a stressful or intolerable situation. Gudjonsson (1992) has identified factors that make people vulnerable to this type of confession. They include fear of being locked in a cell, and mental states that may interfere with coping mechanisms, such as extreme anxiety, depression and bereavement.

The Codes are intended to prevent admissions being made by suspects subject to physical discomfort, pain or exhaustion, which may also lead to coerced-compliant false confessions. Code $C$ lays down requirements concerning heating, cleaning, ventilation and lighting of cells. It calls for particular care when deciding about using handcuffs with mentally handicapped persons. It specifies standards with regard to bedding, requirements as to toilet and washing facilities, clothing for the interview, refreshment, medical attention in the case of suspected illness or injury, even if the detainee does not request it, and rest. The suspect should be asked about the conditions, how he feels about being in custody, how he is drinking, eating and sleeping, and noting any concern about which immediate representation could be made and later reference made if there is an issue of an unreliable confession.

In the case of R. $v$. Delaney (1988) a 17-year-old educationally subnormal man had his conviction for indecent assault quashed. The court heard that he had an IQ of 80 and his emotional arousal was such that he might wish to rid himself of an 
interview as rapidly as possible. The Court of Appeal judges ruled that:

the [trial] judge ... should, have ruled against the admission of these confessions, particularly so against the background of the appellant's age, his subnormal mentality and the behaviour of the police and what they admittedly said to him.

Coerced-internalised false confessions are related to the 'memory distrust syndrome', in which people distrust their own memories and begin to accept suggestions or scenarios put to them by their interrogators. Gudjonsson (1992) has identified a history of mental trauma which affects memory and mental state features such as severe anxiety, confusion, feelings of guilt and bereavement, as factors which make suspects vulnerable to this type of confession.

\section{Documenting fitness}

Clinical records should bear the date and time. The psychiatrist must indicate in the custody record the location of the notes. The Codes require this. The psychiatrist should indicate whether or not the person is fit to be interviewed and, if fit, whether or not the interview should be in the presence of an appropriate adult. It may be appropriate to mention any special precautions for the police (such as keeping language simple) or the appropriate adult (such as being ready to intervene if particular delusional material begins to be introduced).

The records should be kept at least until the trial and in case there is an appeal it may be necessary to keep them for some years. The clinical records, if requested, must be disclosed by the prosecution to the defence.

If the Crown Prosecution Service considers that more information is needed about the basis or significance of the psychiatrist's opinion, he may be asked to prepare a report or a Criminal Justice Act statement (Hiscox \& Davies, 1995). This should be in the form of evidence as it might be given orally at the trial. Box 6 suggests a format.

\section{The limits of expertise}

There are limits to how far fitness to be interviewed can be explored in the police station. The senior registrar should not hesitate to consult the consultant or the consultant indicate that there is some aspect which ought to be addressed later by a consultant in, for example, old age psychiatry or mental handicap.
In R. v. Heaton (1993), in which the defendant was convicted of the manslaughter of his child, the Court of Appeal upheld the trial judge's decision to exclude the evidence of a psychiatrist who stated, from a single interview, that the defendant was "not exceptionally bright," of "dull normal intelligence and is highly suggestible". Collins (1995) has advised barristers:

unless the expert evidence is based on some scientific data or expert analysis outside the experience of the judge and jury, a mere impression even of a highly

Box 6. Format for a statement or report on fitness to be interviewed.

\section{Introduction}

Full name, date of birth and address of suspect Full name, qualifications (including Section 12 status) and professional address of psychiatrist

Where, when and at what time the suspect was examined

Name of anyone else present

At whose request the examination was carried out

Statement of suspect's consent to examination

Basis of opinion

History and examination

Any other relevant history (e.g. police officers, family)

Medical records or other psychiatrists consulted

Diagnosis (including its justification) explained in lay terms

Whether or not suspect is fit to be interviewed

Reasons for opinion (usually only if considered unfit to be interviewed)

If fit to be interviewed

Whether or not an appropriate adult should be present

Any assistance for police and/or appropriate adult to enhance reliability

Any recommendations as to re-examination (if unfitness is likely to be temporary)

Any recommendations as to examination by other psychiatrists or psychologists pre-trial 
qualified doctor will not be admissible [and] one interview by the expert might not be sufficient.

It may be appropriate to recommend examination by a forensic psychiatrist or a forensic psychologist. However, it is important to remember 'the PACE clock'. An opinion on fitness to be interviewed needs to be communicated in time for the police to comply with time limits.

With the benefit of hindsight and in light of subsequent reports by experts, the psychiatrist may have doubts about his opinion. If the psychiatrist is honest and can justify the decision reached at the time, he is unlikely to be criticised. He should admit these doubts and allow the judge to decide whether or not to admit the interview as evidence.

\section{Going to court}

In cases in which there is an issue concerning fitness to be interviewed or reliability, the judge usually hears arguments at a 'trial within a trial' or voire dire and in the absence of the jury. The judge may listen to the interviews and may hear evidence from those who examined the defendant, police officers, the appropriate adult and experts subsequently instructed. The judge then hears arguments by prosecuting counsel and defence counsel as to whether or not the interviews can be admitted and put before the jury. A psychiatrist called to give evidence at such a trial should not hesitate to admit the limits of his expertise. If he has retained legible, detailed, contemporaneous records of the history and mental state, those with greater expertise will be assisted in giving their opinion as to the admissibility or reliability of the interview.

If there are breaches of PACE and they are "significant and substantial" (R. v. Absolam, 1988), then, prima facie, the evidence obtained in consequence ought to be excluded. It does not matter whether the police acted in good or bad faith. If the judge rules the interview evidence inadmissible, the prosecution may take the opportunity to offer no further evidence and the defendant is acquitted. If the judge rules that the jury would be assisted by experts in understanding the mental state of the defendant at the time of the interview, and thus assisted in determining the evidential weight to be placed on the admissions, they may be called again to give evidence before the jury.

\section{Conclusions}

Although the Court of Appeal has considered a number of cases in which fitness to be interviewed by the police is an issue, it is unwise to draw any definite conclusions of law or principle from these decisions. These cases have tended to turn on their own facts and not lay down any specific principle.

The expression "such an adverse effect on the fairness of the proceedings" (s. 78, PACE) requires the judge to look at the circumstances (including any breaches) in the round. He has a very wide discretion as to what evidence he does or does not admit. Where breaches of PACE are established, it makes it difficult but by no means impossible for him to exercise his discretion against a defendant. Whether or not breaches are established, it is in practice very difficult to challenge such an exercise of discretion on appeal.

For the psychiatrist the determination of fitness to be interviewed calls for the highest standards of history-taking and examination, supplemented by the careful consideration of relevant information from appropriate written and oral sources. Upon this assessment may hinge the decision of the court to convict the guilty or acquit the innocent.

\section{Acknowledgements}

I am grateful to Benjamin Nolan, QC, and Dr G. A. Norfolk, Honorary Assistant Secretary of the Association of Police Surgeons, for their comments on earlier drafts of this paper. I am grateful to my senior registrar colleagues whose repeated questions on this topic prompted me to put my thoughts on paper. I also thank an anonymous referee.

\section{References}

*Collins, J. (1995) Confessions by Mentally Handicapped Persons. Archbold Practical Research Papers. London: Sweet and Maxwell.

Gudjohnsson, G. (1984)A new scale of interrogative suggestibility. Personality and Individual Differences, 5, 303-314.

- (1987) A parallel form of the Gudjonsson Suggestibility Scale. British Journal of Clinical Psychology, 26, 215-221.

- (1989) Compliance in an interrogation situation: A new scale. Personality and Individual Differences, 10, 535-540.

- (1992) The Psychology of Interrogations, Confessions and Testimony. Chichester: Wiley.

- (1995) 'Fitness for interview' during police detention: A conceptual framework for forensic assessment. Journal of Forensic Psychiatry, 6, 185-197.

* _ \& MacKeith, J. A. C. (1988) Retracted confessions: Legal, psychological and psychiatric aspects. Medicine, Science and the Law, 28, 187-194.

- Clare, I., Rutter, S., et al (1993) Persons at Risk During Interview in Police Custody: The Identification of Vulnerabilities. Research Study No. 12, Royal Commission on Criminal Justice. London: Her Majesty's Stationery Office.

Hiscox, J. \& Davies, H. de le Haye (1995) Section 9 police statement: A guide for junior doctors. British Journal of Hospital Medicine, 53, 283-287. 
Home Office (1995) Police and Criminal Evidence Act 1994 (s.60(1)(a) and s.66) Codes of Practice. London: Her Majesty's Stationery Office.

Norfolk, G. (1996) Fitness to be interviewed and the appropriate adult scheme: A survey of police surgeons' attitudes. Journal of Clinical Forensic Medicine, 3, 9-13.

- (1997) 'Fitness to be interviewed' - a proposed definition and scheme of examination. Medicine, Science and the Law, in press.

Protheroe, D. \& Roney, G. (1996) Assessing detainees' fitness to be interviewed. Implications for senior registrars' training. Psychiatric Bulletin, 20, 104-105.

* indicates articles of particular interest

\section{Law reports}

R. v. Absolam (1988) Criminal Appeal Reports, 88, 332.

R. v. Crampton (1990) Criminal Appeal Reports, 92, 369.

R. v. Delaney (1988) Criminal Appeal Reports, 88, 338.

R. v. Heaton (1993) Criminal Law Review, 593.

R. v. McGovern (1990) Criminal Appeal Reports, 92, 228.

R. v. McKenzie (1992) The Independent, 28 July.

R. v. Raghip (1991) The Times Law Reports, 6 December.

\section{Multiple choice questions}

1 Fitness to be interviewed by the police:

$a$ is defined in the Codes of Practice of the Police and Criminal Evidence Act 1984

b may influence the admissibility of confession evidence at a criminal trial

c is usually documented in the form of a Criminal Justice Act statement

$\mathrm{d}$ is usually determined by the judge at a voire dire in the presence of a jury

e is usually determined by a police surgeon (forensic medical examiner).

2 Clinical records documenting assessment of a suspect's fitness to be interviewed:

a must be made in the custody record

b should be made available to the defence if requested

c need not be kept after the trial has taken place

$\mathrm{d}$ are the property of the police

e should bear the time of the interview.
3 The 'appropriate adult':

a may be a relative, guardian or other person responsible for the care of the detainee

b is present to advise the detainee

c must be present if there is any mental disorder

d should be prepared to intervene in the interview

e cannot also be the detainee's solicitor.

4 Clinical assessment of fitness to be interviewed:

a can take place in the presence of a police officer

b does not require the presence of the detainee's solicitor

c does not require discussion with the detainee concerning the alleged offence

$\mathrm{d}$ requires the written consent of the detainee

$\mathrm{e}$ is not possible if the detainee is withdrawing from alcohol or drugs.

5 The Codes of Practice of the Police and Criminal Evidence Act 1984:

a give the trial judge discretion to exclude evidence such as confessions in police interviews

b define 'mental disorder'

c define 'mental handicap'

d state that a mentally handicapped person should not be handcuffed

e define the role of the 'appropriate adult'.

\begin{tabular}{|c|c|c|c|c|}
\hline \multicolumn{5}{|c|}{ MCQ answers } \\
\hline 1 & 2 & 3 & 4 & 5 \\
\hline a $F$ & a $\mathrm{F}$ & a $\mathrm{T}$ & a $T$ & a $\mathbf{F}$ \\
\hline b $T$ & b $T$ & b $\mathrm{T}$ & b $\mathrm{T}$ & b $\mathrm{T}$ \\
\hline c $F$ & c $\mathrm{F}$ & c $\mathrm{F}$ & c $\mathrm{T}$ & c $\mathbf{F}$ \\
\hline d F & d F & d $\mathrm{T}$ & d F & d $\mathbf{F}$ \\
\hline e $\mathrm{T}$ & e $\mathrm{T}$ & e $T$ & e $F$ & e $\mathrm{T}$ \\
\hline
\end{tabular}

